\title{
Life and the Structure of Molecules*
}

\author{
A Discussion of the Biological Properties Involved \\ By Amé Pictet
}

Among all the problems which nature presents to the mind of man the most absorbing is undoubtedly that of life itself. Its solution must be sought in all the physical and natural sciences taken as a whole, an demands the employment of the most powerful mean of investigation at our disposal. However, it is upon the science of biochemistry that the principal part of the task devolves. It cannot be doubted, in fact, that if life itself be not a chemical process, at any rate the phenomena of which it is the cause are chemical in phenomen

But biochemistry is itself based upon pure organi chemistry. A fundamental condition, in fact, of the ability to interpret any phenomenon correctly is a exact knowledge of the medium within which it de velops, and in the present case it is to organic chem istry that we must look to establish the nature of the materials of which living creatures are composed. The primary object of organic chemistry is to separate, to purify, to describe, and to analyze the innumerable purify, to describe, and to analyze the innumerable
compounds which we derive from animals and from compounds which we derive from animals and from
plants. But it does not stop here. It has the further plants. But it does not stop here. It has the further
object of endeavoring to comprehend what is terme the constitution of these bodies, $i$. $e$., the intimate architecture of their molecules, the exact positions occupied by each of their atoms and the relations between these atoms. In the great majority of cases this task has been successfully accomplished, and thu there has been performed a tremendous piece of work which, in the phrase of one of our most eminent contemporary physical-chemists, Nernst, represents the most remarkable achievement thus far of the huma intellect.

Let me hasten to add that the enormous sum of labo involved in these researches has not been inspired solely by the speculative interest which attaches to all new knowledge. The chemists who have thus dissected all the organic molecules, who have drawn up the all the organic molecules, who have drawn up the
plans of these minute edifices, have been impelled by plans of these minute edifices, have been impell

two other purposes of a more immediate nature.
In the first place by the attractiveness of synthesi We have learned that the artificial reproduction of natural compounds has no chance of succeeding unless the constitution of the latter is known in its minutest detail. Whenever anyone has attempted to proceed differently, to put the cart before the horse, as we may say, by operating empirically, success has been lacking; the most recent example of this fact is afforde by the fruitless endeavors to manufacture rubber artificially.

Chemists have devoted their attention, in the second place, to questions of constitution, since they have not been slow to recognize the fundamental fact that all the properties of organic compounds, whether of physical, of chemical or of physiological nature, are closel related to the problem of constitution. It is neithe related to the problem of constitution. It is neither the quantity nor the nature of the materials employed in constructing a building which make of it a church, a theatre or a railway station; it is merely the arrangement of the materials; in the same way it is neither the kind nor the number of the atoms in its molecules which make of an organic compound a dye an antiseptic or a perfume. It is solely the manner in which these atoms are grouped with respect to in which these atoms are grouped with respect to to possess the means of preparing with certainty, an at will, any given new compound whose propertie have been determined in advance.

$A$ vast mass of highly interesting relations have thus been established between the constitution of bodies and certain properties, such as color, flavor, density, tinctorial power, rotatory power, pharmacological power, etc. But it is necessary that every domain should be explored, and there is one in particular, namely, that of biological properties, which there has been as yet no attempt to connect with the structure of molecules.

It is this subject which I wish to bring before you. I will begin by limiting it by means of the three questions which follow:

1. Does there exist any relation between the chemica constitution of the body and the role it plays within the living organism?

2. Does there exist any condition of molecular structure which renders a substance useful, injurious or

-An address delivered before the Helvetian Society of Nat ural Sclences. Translated from the Geneva Archives of Phys
and Nat. Sc. for the ScIENTIFIC AMRICAN SUPPLEsEnT. tenance of life, which makes of it, in other words, food or a poison?

3. Does there exist any similar condition whereby the matter of a living cell may be distinguished from that of the same cell when dead; in other words, does death result from a change in the architecture of the molecules?

Before attempting to reply to these questions it ap pears to me desirable to define the special point of the theory of the constitution of molecules upon which $m y$ answers will bear. But I shall confine myself to strictly necessary statements. Further than this need only recall to your minds the essential principle of organic classification.

We have learned by fifty years of patient research hat the organic compounds thus far known, approxi so far as concerns their molecular structure, in spite of their enormous variety.

In the first type the atoms of which they are com posed, namely those of carbon, oxygen, or nitrogen, i the process of satisfying their chemical affinities, eithe wholly or in part, form chains which vary in length and are practically rectilinear. Thus the central portion of the molecule forms a sort of vertebral column upon which other atomic groups are grafted later on

In the second type these same atoms are united under the influence of the same attractive forcse, but they der the influence of the same attractive forcse, but they
form chains whose two ends meet. Thus the skeleton form chains whose two ends meet. Thus the skeleton
of the molecule ceases to be a mere string of atoms ancl becomes a ring. And around the periphery of thi ring similar groups may cluster, just as the flesh of a fruit surrounds its kernel.

Thus we have a distinction between open chain com pounds and cyclic compounds. Today we consider this distinction to be the fundamental basis of organic classification. It corresponds, for example, to the division of the animal kingdom into vertebrates and invertebrates, and is not without a certain analogy to that division since it is likewise based upon the conformation of the skeleton and upon the system of symmetry of the organism. These two great classes of organic compounds are separated theoretically by wide chasm. But this chasm can be bridged. In man cases it is possible to act upon the molecules of bodies by means of appropriate reactions in such a manner as to cause the ends of an open chain to unite (this process is called cyclization) or, on the contrary, to break a closed chain (an operation which may be caller cyclolysis). Thus it is possible to pass experimentally from one type to the other.

To be sure, this passage is incomparably easier in one direction than in the other. One of the characteristics of closed chains is their stability, and it always requires a considerable chemical effort to disunite the links. Cyclization, on the other hand, is far more readily produced; however, it demands a certain in crease of energy necessitated by the bending of th rectilinear chain and the welding together of its two terminal atoms. The question arises as to what forms of energy are capable of performing this work.

In the first place there is heat. Berthelot first demonstrated this by causing a series of open chain sulstances to pass through tubes whose temperature wa raised to a red heat. He thus obtained numerous cyclic compounds and, in particular, the majority of those which are mingled together to form coal tar, that byproduct of the manufacture of gas from which moder chemistry is able to extract so many valuable derivatIves. Berthelot even estalished upon the basis of the experiments his famous theory of the formation of coal tar. According to this theory the coal is entirely decomposed in the course of its distillation into ver simple linear skeleton gaseous products, which products are suddenly cyclisized by contact with the hot walls of the retorts. We shall consider the value of this explanation further on.

But cyclic compounds are not found in coal tar alone. We encounter them in substances which have never been subjected to severe heat, in petroleum, for example. They are particu arly abundant in living or ganisms, and especially in plants. In this case the agent which has produced the cyclization is not calorific energy; we must seek further for the cause, and shall find it directly.

But allow me first to make a preliminary remark. According to what I have just said to you it would seem that the properties of an organic compound must vary absolutely with respect to whether the body be- longs to the open chain cluss or to the class of cyclie substances. But observation shows that this is not true. On the contrary both classes contain alcohols, acids and bases, fiavorous or ordorous substances as well as those which have neither flavor nor odor, anıl both poisonous substances and those which are harmless. The chemical industry derives its perfumes and its explosives, and the art of medicine its drugs, indifferently from one class or the other. Color alone appears to bear some relation to cyclic structure, but this is true only to a limited degree.

IVe are forced to conclude, therefore, that these properties are but little infiunced, or not at all, by the conformation of the skeleton of the molecule; they depend essentially upon the nature of the peripheral groups which surround the skeleton, and which may bn the same in both cases. We have here a fact which is apparently very strange; it is difficult to comprehend why a characteristic so essential from a theoretic point of view as the structure of the skeleton shouls] have no effect upon one of the fundamental properties of the substance.

But it is just at this point that my personal observations enter into the question, and I may state that this anomaly, which would be quite inexplicable, in reality does not exist. I believe I am justified in af firming, on the contrary, that there is an entire ensemble of the fundamental properties of matter which is governed respectively by the cyclic or linear nature of the molecular skeleton. These properties are those which come into play in all the manifestations of life. It is this which I will attempt to demonstrate.

If we would study vital phenomena in their simplest manifestations we must observe them not in the animal but in the plant. Let us consider, therefore, the green plant, the organism upon which devolves the task of transforming the mineral substances of its environment into organic matter, and finally, into living matter which the animal needs only to break down and to burn later in order to utilize the energy which it contains in the potential state.

What, then, is the mechanism of this marvelous synthesis? As yet we do but know it very imperfectly. Rut we know the intermediate products through which it passes. These are the formic and glycolic aldehydes, the sugars and starches, the numerous vegetable acids, asparagin, glycerine, the fatty matters, the lecithins; these substances exist in all plants; we detect their presence in every living cell, together with the proteins which constitute the essential elements of the protoplasm. Apparently, therefore, they may be regarded as the aliments of the cell.

But when we consider the constitution of these bodies we are struck by the fact that their molecules contain only open chains of atoms. None of them exhibit the cyclic structure. Thus we perceive a primary relation between the constitution of the molecule and the role of the vegetable substances. All of these which may be legitimately considered as the dirert and successive product of assimilation, all these whick: contribute to the building and the maintenance of the living protoplasm, belong to the first class of organic compounds. But these substances are far from bein: the only ones which the vegetable kingdom yields. Besides these the plant produces an infinite variety of others which human industry has at all times sought to obtain, not to use as foods but in order to derive a profit from some other of their properties. This is the case, for example, in the great family of the essential oils, the turpentines and the camphors, many representatives of which constitute our most highly appreciated perfumes or condiments. Furthermore, there is a lons series of vegetable pigments and dyes, from chlorophyll down to that interesting group of the anthocyanins or flower pigments, whose systemätic study has been recently undertaken by our former colleague, willstaetter. Then there are the different resins, the rubbers, the tannins, the glucosides and the various bitter or astringent principles. Finally, we have all those numerous nitrogens and basic compounds to which the collective name of alkaloids is given, and which have become our most valuable medicaments for the reason that most of them are endowed with a remarkable physiological action upon the animal organism.

Is the rôle which these substances play in the plant the same as that of the compounds in the first category? It was formerly believed so. Even today many plant physiologists hold this riew, and consider these materials to be reserres of nutrition which the plant will 
utilize at the proper moment for the maintenance of its tissues.

I do not agree with those authorities, and my reasons are as follows: These substances do not appear to me tri be indispensable to the development of the plant as are those in the first category, since many plants entirely lack them. We do not find them stored in the seeds or the roots as are the others. We never en counter them in the living cell, from which they seem ine excluded, but only in special receptacles or tissu in which they are localized and seem to be set aside from the great pathway of proteinogenesis. We do not see them disappear during the course of the life of the plant; on the contrary, they accumulate. It is certain therefore, that they are not intermediary products in therefore, that they are not intermediary products in
the building of living protoplasms. We must seek elsethe building of living protoplasms. We must seek else-
where than in a process of assimilation for the genesis of these compounds, which, without nutritive value for the plant, are yet engendered by it often in very considerable quantities. What, therefore, is their origin and their significance?

Some years ago I formulated a hypothesis upon this subject with special reference to the alkaloids. This hypothesis having been received with considerable favor I now extend it to all compounds of the same order. It is my opinion that, far from being products of assim ilation, they are products of denutrition. They represent the waste matter of plant metabolism. The correspond to the animal products, urea, uric acid, glycocoll, the pigments of the bile, etc. It is not conceivable in fact that the biologic synthesis of the proteins should be performed with a theoretic yield containing no accessory products, that is residues no longer usa ble, any more than is any synthesis whose operation takes place in vitro. Furthermore, in the plant as wel as in the animal similar waste matter, either nitrogenous or non-nitrogenous, must be produced necessarily by the wear of the tissues and all the phenomena of assimilation and combustion. All these products are not only useless but actually injurious to the maintenance of life. They are poisons of which the organism, whether plant or animal, must rid itself at any ism, whether plant or animal, must rid itself at any
price under penalty of auto-intoxication. The animal does this by excreting such products outside itself, but the plant, which lacks excretory organs, can do thi but imperfectly. It must, therefore, resign itself to living with them and confine itself to rendering them inoffensive by keeping them outside the vital circuit, and preventing them from penetrating anew into the living cell whence they came and there exerting their living cell whence they came and there exerting their
harmful action upon the protoplasm. And we see that harmful action upon the protoplasm. And we see that
the plant is successful in this since the compounds in question are never found inside the living cell. It wall, therefore, forms a barrier between the useful substances and the injurious ones; it is permeable by the first and impermeable by the second. Is it possible to form an idea of the mechanism which controls this sifting process?

No physical characteristic (such as solubility, ionization, the colloidal or crystalline state) distinguishes one of these two categories of substances from the other. Neither does there exist any difference of chemical composition between them; they are formed protoplasm itself. In my opinion, therefore, their opposite behavior can be explained only by a difference of molecular structure. Let us examine, therefore, the ficts that are known regarding their constitution.

Researches upon this subject have led to the re markable conclusion, all of whose consequences ar not as yet revealed, that all these products are cyclic compounds. The atoms of carbon in the turpentines, the camphors, and the tannins; the atoms of carbon and of oxygen in the anthocyanins; and the atoms of carbon and nitrogen in chlorophyll and in all the alkaloids are uniformly united in closed chains. As we have seen the reverse is true of the nutritive subhave seen the reverse is true of the nutritive sub-
stances of the cell. I behold, therefore, in this different arrangement of atoms the reason why the molecules of one kind are able to penetrate the living cell, whil those of the other kind are excluded. An iron wire will pass through a very narrow opening if introduced rolled into a circle. In the same way the intermolecu rolled into a circle. In the same way the intermolecu
lar apertures of the cellular walls will allow the flexible chaplets of the open chains to pass, while they will oppose the entry of the massive rigid rings which form the cyclic molecule.

But the dejecta of metabolism are originally open chain bodies like the substances from which they pro ceed. Hence, it is only by sudden jerk, so to speak, that they require the cyclic structure which renders them inoffensive. There is a reaction of the living plant against the toxic principles which it produces, and this reaction consists in a modification of the in-
timate structure of these principles; the plant defends
Itself against the poisons it produces by causing their cyclization. It is evident, therefore, that there are in the plant organism two processes of parallel syntheses in one of which the atoms are united by simple juxtaposition to form long open chains which finally constitute the complex molecules of the proteins, while he other, carrying on a regular sewerage system, leanses the orginism of all the detritus left behind by he tirst synthesis, by winding up into rings all those fragments which are no longer capable of aiding in the construction of the edifice, or which beco

This hypothesis having been formulated, it remained to verify it by experiment and to show how cyclization operates in the plant. It is this which I have endeavored to do by means of my investigations concerning the alkaloids. Starting with the idea that in organic synthesis the best method of attaining our object is to imitate nature, I have always endeavored in my attempts at the artificial reproduction of vegetable alkaloids to operate under conditions resembling as closely as possible those which occur in the living plant. It was this idea which presided over the recent researches conducted in my laboratory by Messrs. Gams, Spengler, Kay and Malinovski and by Mlle. Finkelstein-researches which led to the synthesis of berberin and of everal of the alkaloids of opium.

As points of departure for our operations we always chose on the one hand substances which are known to and on the other hand compounds such as formic alde hyde, which are primarily derived from the carbon dioxide of the air. By combining the one kind with dioxide of the air. By combining the one kind with
the other kind we succeeded in obtaining cyclic alkaloids, and these were found to be identical with those produced in the tissues of plants.

I even succeeded, in collaboration with $M$. Chou, in oltaining alkaloids directly by hydrolyzing in vitro the albumens themselves in the presence of formic ildehyde.

It seems to be clearly proved, therefore, that the alkaloids are formed in the plant $5 y$ the cyclization of the products of decomposition of the proteins; and by
analogy we are justified in attributing the same origin to all similar compounds.

To sum the matter up, a complete parallelism is to be found between the two great divisions of organic compounds, based on the structure of their molecular skeleton and upon the rôle which they play in the organism of the plant. Only the open chain compounds are capable of sustaining the life of this organism, while the closed chain compounds, which we find in abundance in certain plants, are merely dejecta without nutritive value and made inoffensive by the mere would contain none of these compounds.

But a serious objection to this conclusion immediately presents itself. Every chemist and every botanist will thrust it upon me, saying: In the enumeration of the substances in the plant which do not contribute to the formation of its protoplasm you have omitted the most important of all, the cellulose, that substance which is so essential from the morphological point of view, and which throughout the whole extent of the kingdom of plants forms the wall of the cells and of the vessels, exerting a fundamental rôle in the mechanical protection of the protoplasm by providing the necessary envelope enabling it to organize itself into more or less rigid and resistant tissues.

It seems indispensable, my critic will continue, that the substance upon which this function devolves should possess sufficient chemical stability to resist the multiple actions which take place in the plant. It is necessary that it should remain outside the general metabolism. If the ideas which you have developed are correct this indifference must result from its molecular structure, and cellulose must possess the cyclic structure like all the other compounds which the plant excludes from the vital circuit. But all chemical treatises place cellulose beside starch among the open chain compounds, and this fact alone is sufficient to demolish the framework of your theory. I must acknowledge that it would be impossible to reply to this objection if it rested upon a solid basis, $i$, e., upon an exact knowledge of the constitution of cellulose. But this constitution has thus far never been determined, and the analogy with starch is not sufficient to establish it. I believe, on the contrary, that cellulose must occupy a place remote from that of starch as regards its classification, and that it should be placed among the compounds possessing the cyclic structure. A series of experiments conducted by me with the assistance of MM. Ramseyer and Bouvier enable me to offer you some proof of the theory which I have just advanced. These experiments were instigated by the following considerations.
The chemical phenomena which cause the decomposition of the plant after its death differ according to the conditions in which they occur. If the plant is left to itself in the open air, its nitrogenous matters first undergo a rapid putrefaction, with the formation of ammonia, which is absorbed by the soil, and of carbon dioxide which returns to the atmosphere. The nonnitrogenous substances, and cellulose in particular, resist longer, but finally they also disappear by means of a slow combustion, whose agent, either direct or indirect, is the oxygen of the air.

If the dead plant is more or less covered with the soil instead of remaining in the open air, this action of the oxygen is retarded, and there is a formation of humic matters, substances which are still very illdefined as regards the chemical point of view, but of which it is known that they are the products of the in:complete oxidation of the cellulose, and that they exhibit the characteristics of phenols, $i$. $e$., of cyclic compounds.

Finally, if these same vegetable matters are entirely removed from the action of the air, either by immersion in water or by being covered with large masses of eurth, as is the case where vast geologic dislocations have occurred, they still undergo a slow transformation. But this change can no longer be considered an oxidation; it is a decomposition of a special sort of whose laws and whose agents we are still ignorant, but with whose ultimate products we are well acquainted-these products are our fossil combustibles of various periods, including lignite, soft coal and anthracite. It cannot be doubted that it is the cellulose which provides the essential matter of these carbons of the earth. In this transformation the cellulose loses a part of its oxygen and of its hydrogen and consequently contains a higher percentage of carbon. But since this decomposition takes place at a low temperature it involves only the periphery of the molecule the carbonized skeleton is not to believe, therefore, that the structure of this skeleton is identical in coal and in cellulose, so that by determining it in the former, we discover its nature in the latter.

Unfortunately, although coal has been used as a combustible for a couple of centuries, and though for a hundred years there have been extracted from it by distillation three products of such vast industrial importance as illuminating gas, coal tar and coke, we are still almost entirely ignorant, strange to say, of its chemical nature. Is it possible to deduce this nature from the study of the products of this distillation? We know, as I but just now stated, that coal tar is formed exclusively of cyclic compounds. The same thing is true of coke; the fact that it furnishes through oxidation aromatic acids assures us that the atoms of carbon which compose it are united in closed chains. Does this mean that we may attribute the same structure to the materials whence they proceed? Such a deduction would be absolutely unjustified, for these materials have been subjected during the distillation of the coal to temperatures of from $800^{\circ} \mathrm{C}$. to $1,000^{\circ} \mathrm{C}$ and we know by the experiments of Berthelot that these temperatures are amply sufficient to cause the cyclization of all the open chains.

To avoid this objection it would be necessary to eliminate the idea of the cyclization produced by heat during the decomposition of the oil. It is this which I endeavored to accomplish with the aid of my two admirable collaborators by performing the distillation of the coal in a vacuum, by which means we were able to prevent the temperature from rising above $450^{\circ} \mathrm{C}$. We obtained a special form of coal tar and a new kind of coke. But the study of this vacuum coal tar and this vacuum colie revealed the fact that both of them are exclusively cyclic in nature, just as are ordinary cral tar and ordinary coke. We conclude, therefore that the cyclic compounds pre-exist in the coal and certainly form the major portion of it. It is our opin ion, moreover, that these experimental results involve the three following consequences:

1. Berthelot's theory with regard to the formation of coal tar can no longer be regarded as giving a precise interpretation of the facts. We can no longer consider all the derivatives of coal tar, which the chemical industry has so brilliantly utilized, to be products of pyrogenation as had been believed. It is not to the heat of the gas retorts that they are in debt for their famous aromatic nucleus which is so rich in valuable properties. This nucleus already existed, although in a more hydrogenated st:ate, in the plants of the carboniferous epoch. The whole science of aromatic chemistry is thus shown to depend upon the chemistry of the plant

2. The vacuum coal tar is, in reality, nothing other than petroleum; it possesses the odor, the density, the (Continued on paos 59) 
cial features that they present; but as atolls occur in association with barrier reefs in the Caroline, Society, Fiji and other groups, and as the central islands within the barrier reefs present features which, although perfectly accounted for by Darwin's theory of intermittent subsistence, cannot be accounted for by the Glacialcontrol theory, its apparent success in explaining atolls is thereby discredited, all the more so in view of the recent discussion by skeats of the boring in the Funafuti atoll (Amer. J. Sci., New Huven, 45, 1918, 81-90). futi atoll (Amer. J. Sci., New Haven, 45, 1918, 81-90)
'The chief value of the ingenious Glacial-contro theory may therefore be found not so much in its postulate of the prevalent stability of reef-bearing islands or in its assumption that reef corals were killed and that reef-bearing islands were abraded while the ocean was chilled and lowered in the Glacial period, but in the emphasis that it gives to changes of sea level from climatic causes as a factor in the coral-reef problem; for it is manifest that if the cost-glacial rise of sea level coincide in time with the subsidence of an island the resulting submergence will be at an accelerated rate and of an increased amount; while if the fall of se: level occasioned by the oncoming of a glacial epoch coincide with a subsidence, the resulting submergence will be at a retarded rate and of a decreased amount It cannot however be supposed that two processes so It cannot however be supposed that two processes so
unlike in cause as external climatic changes and interunlike in cause as external climatic changes and inter-
nal crustal deformations should be closely related in time; their coincidences must be fortuitous. Through out the central Pacific the rate and amount of recent submergence have not been as a rule too great to be compensated by reef upgrowth; witness the abundant atolls and barrier reefs. But in the region of the Australasian archipelagoes compensation of submergence by reef upgrowth has frequently been unsuccessful witness the rarity of well developed barrier reefs and the almost entire ausence of atolls. As the climatic clianges of ocean level must have been everywhere the same, the factors which have determined the success or the failure of reef upgrowth would appear to

the rate, the amount and the date of subsidence.

It may be added that submarine banks, of such form that they are best accounted for as drowned atolls, are rare in the Pacific. A group of ten or more of them is known in an island-free space north of Fiji; severa extensive banks also occur in Tonga. Exception must therefore be made in favor of a rapid submergence only for these relatively few examples of submerged $\mathrm{Pa}$ cific atolls, and the rule that the great majority of I'acific atolls have not been submerged faster than the rate of reef upgrowth is thereby proved. In the Indian ocean, on the other hand, the number of submarine ocean, on the other hand, the number of submarine
vanks vears a larger proportion to that of atolls, and the Indian ocean is generally regarded by geologist as the seat of greater and more recent movements of depression than the Pacific. Recent and rapid subsidences of moderate amounts may therefore be plausibly regarded as of more general occurrence in the Indian than in the Pacific ocean. The recent date and the ripid rate of subsidence appear to be of greater imripid rate of subsidence appear to be of greater im-
portance than its amount in the case of the Great Chagos bank, where the submergence does not seem great enough to drown the reef-building corals. Her the muddy central area is 40 or 50 fathoms deep; it is bordered by an irregular sandy bank from one to 5 miles or more in breadth and from 15 to 20 fathoms in depth, on the outer margin of which rises a rim about a mile in width, and only 5 or 10 fathoms in dejth; singularly enough, there is little living coral on the outer rim, though knobs of growing coral rise from the central depression. The diameters of the whole mass range from 50 to 75 miles; its form sug gests that a prolonged stationary period, during which a bruad atoll-reef was developed, was followed by a subsidence of about 10 fathoms, after which a shorter stationary period permitted the upgrowth of a narrower reef; then a rapid and presumably recent subsidence reef; then a rapid and presumably recent subsidence
of 5 or more fathoms ensued, since which no effective of 5 or more fathoms ensued, since which no effective
reef growth has taken place, possibly because, according to Daly's suggestion, the submerged corals wer smothered by wave- and current-shifted sediments.

Unfortunately no archipelagoes comparable to those of the Australasian region are present in the Indian ocean to give evidence in the case, but it may be noted that a few high islands which occur in association with the Indian ocean banks - chiefly the granitic islands in the area of the great Seychelles bank-have narrow and unconformable fringing reefs on their deeply eroded and well embayed shores; thus they repeat in a small way the more abundant and therefore more compulsory evidence that is provided by the charts of the Philippines. Further details on these topics are given in an article on "Submarine Banlss and the Coral Reef Problem," now in course of publication in the Reef Problem," now in course of publication in the
Journal of Geology, and in an article on the "SubsiJournal of Geology, and in an article on the "Subsi-
dence of Reef-encircled Islands," soon to appear in the Bulletin of the Geological Society of America.

\section{Life and the Structure_of Molecules} Continued from pape 5 נ)

fluorescence and the slight rotary power of the latter. All the definite bodies which we extracted from it were found to be identical with other bodies which have been isolated from the petroleums of Canada, of California or of Galicia. We have thus proved, for the first time, that there is a relation of a chemical nature between these two natural products of vast importance, namely, coal and petroleum. Does this relation imply a common origin, and will it provide an argument for those who believe that petroleum, like coal, was of vegetable origin? For my part I believe this to be true, but to discuss the point in this place would lead me too far away from my subject.

3. If coal, as we believe we have demonstrated, is formed of a mixture of cyclic substances, we can scarcely refuse to attribute the same structure to cellulose which, of all the substances contained in plants is certainly that which has played the largest part in the forroation of coal. I am justified, therefore, in believing that the criticisms of my theory in this respect are not sustained, and that, on the contrary, my hypothesis finds a fresh example to suport it.

Let us pass now at a single bound over the entir distance which separates the primary products of vegetable assimilation and its ultimate product which is living matter. And let it be clearly understood to begin with that I employ this term, living matter, only by way of abbreviation and to avoid lengthy circumlocutions. We cannot attribute life to matter itself; fact, there is no such thing and there can be no such
thing as a living molecule and a dead molecule. Life thing as a living molecule and a dead molecule. Life and by that very fact it remains outside the domain of pure chemistry.

It is none the less true that the contents of the liv. ing cell must differ in chemical nature from the contents of the dead cell, and it is from this point of view alone that the phenomenon of life is related to my subject; and it is also from this point of view that it remains to examine whether the ideas which I have laid before you can be utilized for the purpose of its interpretation.

A living cell is an extraordinarily complex organism Ir its chemical composition as well as in its morphois a mixture of the most diverse substances; but if eliminate, on the one hand, that portion of these subeliminate, on the one hand, that portion of these sub-
stances which are in process of assimilation, and on stances which are in process of assimilation, and on
the other hand those which constitute the residuum of nutrition and which are in process of being excreted, we have left only proteic or albuminous matters which must be regarded, if not as the essential agent of life, at least as the theatre of its manifestations. They alone, in fact, possess the two eminently vital faculties of constructing their molecules from those of their environment and of reacting to the slightest excitations, whether physical, chemical or mechanical. They rank, therefore, among the most labile organic compounds which we know, i. e., they possess a sort of fluid equilibrium which is maintained by a constant shifting of matter, and it is this very lability which enables them t) support the vital phenomena. During the life of the cell they are in a state of perpetual transformation and never arrive at a state of stable equilibrium until after the death of the cell; or, rather, as we might better say, the death of the cell is nothing more than the result of stabilization of the proteic molecules.

Is this stabilization chemical in nature in the sense that it proceeds from a modification of the molecular structure? To know whether this be the case and what this modification consists of it would be necessary to know the constitution of living albumen and also that of dead albumen. But chemistry is entirely or almost entirely ignorant of the first, for the first effect of the processes of investigation which it employs is to kill every living cell. The slightest elevation of temperature, the contact with any sort of solvent, and still more that with even the mildest reagents, occasion that transformation which ought to be avoided, and thus the chemist has only dead albumen left in his hands. It is only the latter, therefore, which he has been able to study. Thanks to the labors of a galaxy of eminent savants, at the head of whom we must place our two honorary members, Emil Fischer and Abderhalden, we are familiar with the constitution of the albumens, if not in the minutest details, at least along general lines. We know in particular, as respects our present point of view, that the extremely complex molecule of these bodies is formed by the assemblage of a very large number of chains, some of which are formed of atoms of carbon alone, others of atoms of carbon and of nitrogen, but all of which are closed chains. The albumens derived from dead tissues are cyclic in struc-

But the question is whether this is true of these al- bumens while they still form an integral part of the living protoplasm, and how we can determine it. A highly interesting observation made by Loew will give us the beginning of an answer to these questions. Loew observed that all the chemical reagents which are capable in vitro of attacking the aldehydes and the primary bases, or of acting upon the aldehydic and aminisrenic groups which characterize them, invariably act as poisons to living protoplasm. These same reagents, on the contrary, exert no influence upon dead albumen. From this circumstance Loew logically concludes that the molecule of living albumen contains the said groups, while the molecule of dead albumen no longer possesses

These two groups of atums possess very active functions throughout the whole extent of organic chemistry. But these functions are opposite in character, which leads them to react upon each other by the excliange of the elements which compose them. This exchange does not take place in the living albumen, since in that the two groups co-exist side by side; it operates after the death of the cell, since neither of these two groups can be detected in its albumen. This stabilization of the proteic molecule must be due, therefore, according to Loew, to the saturation of one of these two groups by the other. This observation appears to me to be of capital importance; but its author has not pursued it, in my opinion, to the ultimate limit of its theoretic consequences. I will attempt to do this in his place.

By the conditions of their very nature the groups of atoms to which I refer can in no case form an integral part of a clused chain. Being both of them monovalent they are capable of forming a part only of open chains. Their existence in living albumen necessarily implies, therefore, the presence of these chains therein.

But the union of two atomic groups forming a part of the open chain cannot occur without the closing of this chain; at the same time the disappearance of both active groups also necessarily involves the abolition of a portion of the activity of the contents. It is like a man who clasps his hands together or crosses his arms; by doing this he loses the best part of his means of action. The stabilization of living albumen involves cyclization therefore. When the albumen of the cellular protoplasm closes its open chains into the ring form it enters into equilibrium and a state of rest. Its period of activity terminates in the same manner as that of all the substances which combine to maintain it. Both in the one case and the other cyclization is death. It is a momentary death, of course, and destined to be followed after a longer or shorter lapse of time by a resurrection which will again put in circulation the atoms temporarily immobilized. It is evident, in fact, that if all the molecules which have undergone cyclization life would soon disappear from the surface of our globe.

Therefore, all that I have said applies only to the organic compounds which form a part of the living plant. As soon as they are taken away from this other agents come into play which proceed more or less rapidly to the demolition of all the molecules and to general decyclization. The dead plant immediately tinds itself engaged in a struggle with the microbes of putrefaction which attack its albumens, and with the oxidizing ferments which burn its cellulose. Or, perhaps, we behold the intervention of the digestive ferments of the herbiverous animals which are likewise cyclolytic. Here, as elsewhere, the two kingdoms complete and mutually assist each other, and it is the same atoms which, passing from one to the other in aggregates of various srtucture, maintains the eternal existence of both.

Such are the ideas which I have felt myself able to lay before you concerning the relations which exist between molecular structure and life. I have lifted but a small corner of the veil which hides the mystery, but I believe I have succeeded in answering the three questions with which I began by showing:

1. That the vital phenomena are connected with a special structure of the organic molecule;

2. That only the arrangement of the atoms in open chains permits the manifestations of life and its main tenance;

3. That the cyclic structure is that of substances which have lost this faculty

4. And finally, that death results, from a chemical point of view, from a cyclization of the elements of the protoplasm. The serpent holding its tail in its mouth, which was the symbol of eternity among the ancients might be regarded as that of death by the modern biocliemist.

I have spoken to you only of the chemistry of the plant. It remains to be seen whether my interpretation can be applied also to the phenomena which take place in the animal organism. 